mortality rate of less than 20-30\% but significant psychological sequelae in up to $64 \%$, neurologic deficits in $54 \%$, and major handicaps in $42 \%$ that include blindness, spasticity, mental retardation, and occasionally, seizures. Mild residual problems involve speech and language (30\%), learning (30\%), and behavior and emotion (50-70\%). Factors that predict sequelae are 1 ) severe symptoms, 2) prolonged coma, and 3) young age group. Ammonia and SGOT levels do not correlate with prognosis. (Svoboda WB. J Nat Reye's Syndrome Foundation 1987; $\underline{7}$ :34-37).

COMMENT: This report was one of 10 invited papers presented at the 12 th annual meeting of the Nat Reye's Syndrome Foundation. The author points out that in the 1960's the question was "What is Reye's Synarome?", in the 1970's, "Will the child survive?", and in the 1980's, "What sequelae may be expected and how should these be managed?"

In one report of 16 survivors of Reye's syndrome (Benjamin PY et al. Crit Care Med 1982; 10:583) significant emotional problems in 56\% of the children and $94 \%$ of their mothers contrasted with relatively good intellectual and academic recovery. None had severe neurologic sequelae and 14 ( $88 \%$ ) had IQ's within the normal range. The decreasing mortality rate of Reye's syndrome has focused attention on the quality of life of survivors and their parents.

\title{
ATTENTION DEFICIT DISORDER AND METHYLPHENIDATE
}

1) Members of the Departments of Social Ecology and Psychology at the University of California, Irvine 92717 and Los Angeles 90024 have investigated the effects of methylphenidate on the social behaviors of hyperactive children ages 6 to 11 during unstructured activities in an outdoor summer program. When a low dose of methylphenidate $(0.3 \mathrm{mg} / \mathrm{kg})$ was compared to placebo, 15 of 24 children treated showed medication-related decreases in negative behavior. The beneficial effects in younger children were greater than in older children and incremental improvements occurred between low and moderate dose levels $(0.6 \mathrm{mg} / \mathrm{kg})$. Neither low nor moderate doses of methylphenidate increased social withdrawal. (Whalen CK, Henker B et al. Natural social behaviors in hyperactive children: Dose effects of methylphenidate. J Consult and Clin Psychol 1987; 55:187-193).

2) A psychologist, psychiatrist, and pediatric neurologist at the University of Rochester, Rochester, NY 14627 collaborated in a study of the effects of methylphenidate on 19 adolescents with a childhuod history of attention deficit disorder. In a double-blind crossover trial of methylphenidate ( $40 \mathrm{mg} / \mathrm{day}$ ) compared to placebo for 3 week periods, parents and teachers reported drug-induced improvement in attentiveness and behavioral compliance and lessened overactivity. Subjective ratings of dysphoria (sadness or unhappiness) were lower and heart rates were higher during stimulant therapy at this dose level. (Klorman R, Coons HW, Borgstedt Ad. Effects of methylphenidate on adolescents with a childhood history of attention deficit disorder: I Clinical findings. J Amer Acad Child Adol Psychiat $1987 ; \underline{26}: 363-367$ ).

COMMENT: These studies provide further evidence for the beneficial effects of methylphenidate in the treatment of children and adolescents with attention deficit disorders and hyperactivity. Those who favor the use of stimulants may be encouraged by the finding that discuptive behaviors were reduced successfully without affecting overall sociability. 